\title{
ПОЛИТИЧЕСКАЯ СТРУКТУРА РИМСКОЙ РЕСПУБЛИКИ V-VI ВВ. ДО Н.Э. (СЕНАТ, КОМИЦИИ, МАГИСТРАТЫ)
}

\section{POLITICAL STRUCTURE OF THE ROMAN REPUBLIC V-VI CENTURIES. BC. (SENATE, COMMISSIONS, MASTERS)}

\section{S. Kovalev}

Summary: The article is devoted to the study of the features of the construction and functioning of the political structure of the Roman Republic of the 5th-6th centuries. BC. Special attention in the research process is paid to the senate, comitia, magistrates. The powers of the Senate and its distinctive characteristics are considered. Also, special emphasis is placed on the institution of consuls, which occupied a special place in the political and legal system of the Roman Republic. In addition, special emphasis is placed on the concept of imperium, which defined the fullness of the highest executive power in the Roman state.

Keywords: power, senate, Roman Republic, magistrate, comitia, powers, elections.
$\Phi$ еномен Римского государства и римского права выходит за рамки того, что обычно понимают под «государством» и «правом». Это был отдельный мир, сравнение которого с другими - более поздними формами культурно-исторического бытия - дает лишь очень приблизительную картину того, что происходило на самом деле, и почти не объясняет причин колоссального вклада Древнего Рима в духовную, политическую и правовую сокровищницу человечества [1]. На сегодняшний день не подлежит сомнению тот факт, что римская цивилизация глубоко изменила жизнь людей и характер человеческих отношений. Это привело к появлению не только новых технологий, но и нового образа мышления, которые во многих случаях сохранились на века, а некоторые из них дошли и до нашего времени.

Достаточно сказать, что существующая в большинстве европейских стран континентальная модель правления имеет свои истоки в Древнем Риме, поскольку ее правовая форма и основные элементы сложились еще в период эволюции Римской империи. В процессе формирования единого централизованного государства и перехода от античной республики к империи неримское население вело постоянную борьбу за равные с гражданами Рима политические и гражданские права. Особенно острым был вопрос о политическом равноправии, которое значительно расширяло возможности населения других общин - municipes (неримских граждан) для
Ковалев Станислав Сергеевич

Преподаватель-исследователь, Санкт-Петербургский Государственный Университет stanis12021@yandex.ru

Аннотация: Статья посвящена изучению особенностей построения и функционирования политической структуры Римской республики V-VI вв. до н.э. Детально в процессе исследования рассмотрены сенат, комиции и магистраты. Также отдельно выделены полномочия сената и его отличительные характеристики. Особый акцент сделан на институте консулов, который занимал ведущее место в политико-правовой системе Римской республики. Кроме того, акцентировано внимание на понятии «imperium», которым определялась полнота высшей исполнительной власти в Римском государстве.

Ключевые слова: власть, сенат, Римская республика, магистрат, комиции, полномочия, выборы.

участия как в общественно-государственной, политической жизни, так и в торгово-экономических отношениях на основе римского частного права [2].

На сегодняшний день республиканская форма правления, возникшая в Риме после изгнания царей в 509 г. до н.э., является господствующей во многих странах мира. Конечно, она не избежала эволюции, стремясь соответствовать требованиям времени, однако ее основы, заключающиеся в выборности высших органов государственной власти и ограничении их полномочий временными рамками, были заложены в Древнем Риме еще в VI в. до н.э. и сохранились до нашего времени.

Следует отметить, что римское наследие в сфере государственного правления не утратило своей актуальности и сегодня, в условиях современного меняющегося мира.

В то же время, несмотря на значимость рассматриваемой проблематики, необходимо обратить внимание на тот факт, что социально-политическое развитие государства римлян в V-VI вв. до н.э. не является объектом детального исследования в отечественном антиковедении. Советскими историками отдельные аспекты данной предметной сферы изучались с позиций чрезмерно тесной связи событий социально-политической борьбы в обществе с судьбой рабовладельческого строя в рим- 
ском государстве. Среди зарубежных исследователей существуют разногласия во взглядах на ряд аспектов политической жизни Римской республики.

Кроме того, некоторые авторы сосредотачиваются преимущественно на формальной, юридической стороне государственного устройства Древнего Рима, в то время как другие уделяют больше внимания рассмотрению сакральной стороны римского политикума.

Таким образом, вопрос появления властных институтов, их эволюция и, в общем, эффективность власти в истории древнего Рима вызывают исследовательской интерес и обусловливают выбор темы данной статьи.

В доступном виде (в ряде списков) дошел до нас важный сводный памятник римского права, а именно сборники Юстиниана (VI в. н.э.). Помимо него можно отметить произведения римских историков и философов, главным образом - Полибия, Цицерона, Тита Ливия, Дионисия Галикарнасского, Тацита, Светония, Плутарха, Авла Гелия. В произведениях этих авторов содержится много важных свидетельств относительно истории управления в Древнем Риме.

Вопрос государства и права Древнего Рима исследовали такие ученые, как: Панасенко Д.А., Кудратов A.O., Пономарева M.C., Valentin Arena, James Tan, Adda B Bozeman, Matthew Dillon, Luigi Capogrossi Colognesi.

Особенности формирования органов государственного управления рассматривались как в работах древних авторов, в частности Марка Туллия Цицерона, мыслителя эпохи Просвещения (Монтескье Ш.Л.), так и в публикациях современников Stevenson, Tom Ryan, Alan, Kewes, Paulina, Gustafson, S.M., Власовой О.А., Маркова К.В., Николаева Д.М., Шалов В.А., Колдин Д.А.

Исследование социально-политического развития Римской империи основательно осуществлялось западноевропейскими историками. Они расширили круг нарративных источников, более критически относились к свидетельствам древних авторов, использовали данные эпиграфики и нумизматики. Среди наиболее известных работ целесообразно выделить Kathryn Tempest, Jan H. Blits, Melissa S., Laura Tingle, Joy Connolly.

Наряду с работами общего характера также появились исследования, в которых освещается развитие отдельных регионов империи, им посвятили свои труды Blom, Christa Gray, CatherineSteel, Lee L. Brice;Danielle Slootjes, Jed W. Atkins, Nigel Rodgers.

Отечественные исследователи пытались выяснить причины упадка римского государства, изучали историю главных правительственных учреждений римлян, эволюцию их вооруженных сил, историю правления отдельных римских императоров (Ткаченко Д.Н., Рогачевский Л.А., Душенко К.В., Медовичев А.Е., Васильев А.В.).

Вместе с тем, несмотря на значительный научный потенциал, а также отдавая должное достижениям и наработкам ученых, следует отметить, что ряд вопросов, касающихся эволюции римского сената и его роли в политической жизни римского государства, принципов формирования и основных полномочий высших выборных государственных магистратов - консулов и преторов, остается открытым и требует дальнейшего более детального исследования.

Кроме того, отдельного внимания заслуживает исследование специфики древнеримского общества, в пределах которого нашли свое сочетание как элементы монархизма и аристократизма, так и элементы подлинного народовластия.

Таким образом, цель статьи заключается в проведении анализа политической структуры Римской республики V-VI вв. до н.э. в разрезе ее ключевых элементов - сената, комиций, магистратов.

Методологическую основу исследования составляют принципы историзма и объективизма, а также специальные исторические методы, такие, как хронологический, синхронный, диахронный, сравнительноаналитический. Важное место занимает метод комплексного анализа источников, который предполагает не только сопоставление данных нарративных материалов, но и сравнение сообщений античных авторов с информацией из других документов. Кроме того, в процессе исследования применяется метод системного анализа, с помощью которого осуществляется реконструкция политико-правовых норм Римской республики.

Итак, прежде всего, необходимо отметить, что на V-VI вв. до н.э. приходится республиканский период развития римского государства, это определяет соответственно и его политическую структуру. Как свидетельствуют исторические источники, в данный период родоплеменной строй постепенно приходил в упадок, тогдашний римский царь Сервий Туллий (578-534 гг. до н.э.) провел реформы, которые нанесли удар родовой организации и привилегированности патрициев, ликвидировали первобытнообщинный строй и окончательно образовали государство. Царская власть приходит в упадок и в 510507 гг. до н.э. и в Риме устанавливается республика [3].

Римляне называли свое государство «respublika», под которым понимали общее, общественное дело. Именно в период Ранней республики в Риме развиваются органы управления и государственный аппарат. Высшие 
государственные должности становятся выборными, а верховная власть формально переходит в руки народа. Конкретно, вся власть сосредоточивается в руках патрицианского сената и назначенных ими магистратов.

По форме государственного правления Рим в V-VI вв. до н.э. был аристократической республикой, к органам управления которой принадлежали:

1. Народное собрание 3-х видов (куриатные комиции (проводили усыновление, религиозные обряды), центуриатные комиции (сборы войска), трибутные (собрание граждан по территориальному принципу - общие и плебейские).

2. Сенат утверждал принятые законы, распоряжения, касающиеся общественной безопасности, бюджет государственных и военных расходов, проводил внешнюю политику.

3. Магистратура, которая осуществляла исполнительную власть (принуждение в случаях невыполнения ее распоряжений, задержание нарушителей, предание их суду, наложение ареста на имущество). Магистраты делились на ординарных (консулы, преторы, цензоры, трибуны, эдилы, квесторы) и экстраординарных (диктатор, начальник конницы).

Рассмотрим эти составляющие власти в Римской республике более подробно.

Народное собрание - высший орган управления в период ранней Римской республики, в состав которого входили патриции и плебеи. Народное собрание было наделено законодательной, управленческой и судебными функциями.

Куриатные комиции после реформ Сервия Туллия потеряли политическое значение, однако сохранили формальное право утверждения должностных лиц, избранных другими собраниями, а также право утверждения завещаний и актов усыновления.

Центуриатные комиции были важнейшим видом народных собраний, которые избирали магистратов (консулов, преторов, цензоров), принимали законы, рассматривали жалобы лиц, осужденных консулами к смертной казни или крупному штрафу «provocatio ad populum»[4].

Трибутные комиции делились на два вида:

а) общее собрание трибы, в которых принимали участие и патриции, и плебеи;

б) сборы плебеев данной трибы.

Большее значение с точки зрения формирования общественного правопорядка имел второй вид сборов (центуриатные комиции), поскольку они принимали ре- шения, которые приравнивались к разновидности публичного закона - плебисцита.

Сенат. Римляне создали политический институт, который не только эффективно служил интересам государства более тысячи лет, но и стал образцом для подражания уже в новое и новейшее время во многих государствах. Это был римский сенат (от senex - старик, старейшина) [5]. Круг дел, которыми руководил сенат, был довольно широким. В административной сфере сенат имел право издавать общие постановления, касающиеся благоустройства и общественной безопасности. Кроме этого, согласно обычаю, любая административная мера, до ее осуществления, выносилась на обсуждение сената.

Что касается области финансов, то сенат составлял бюджет и устанавливал налоги. В распоряжении сената находилась государственная казна. Все это ставило магистратов в непосредственную зависимость от сената. Сенату также принадлежало центральное управление военными делами. Он определял время и количество набора в армию, а также состав контингентов: граждане, союзники и т.д. Сенат выносил постановления о роспуске войска, под его контролем проходило распределение отдельных воинских соединений или фронтов между военачальниками. Сенат устанавливал бюджет каждого военачальника, назначал триумфы и другие знаки почета полководцам. От сената зависело продолжение войны или заключение мирного договора. В особых случаях сенат имел право ввести чрезвычайное положение. Именно при внешних угрозах или в случае беспорядков внутри страны сенат имел право принимать чрезвычайные меры, издавать распоряжения о назначении диктатора, делегировать магистратам чрезвычайную и неограниченную власть и т.д.

Кроме того, в полномочия сената входил высший надзор за культом. Он устанавливал праздники, вводил очищающие жертвоприношения, а в наиболее серьезных случаях растолковывал значение богов (ауспиции), контролировал иностранные культы.

Решение сената называлось декретом, или сенатосконсульством. Заседания сената - ассамблеи - проходили по инициативе магистрата. Это мог быть консул, преTop, а с IV в. до н.э. - народный трибун. В период ранней Республики Сенат состоял исключительно из патрициев и только c V в. до н.э. (с 444 г. до н.э.) в его ряды начали попадать богатые плебеи [6]. Имена всех сенаторов заносили в специальные списки (поэтому их начали называть «conscripti» - «приписанные»).

Таким образом, указанные обстоятельства позволяют сделать вывод, что сенат в ряде отношений играл глав- 
ную роль в управлении Римом, это был орган, в распоряжении которого были сконцентрированы различные рычаги власти, то есть он реально выполнял распорядительную, а в связи с этим - в определенной степени и законодательную функцию.

Право назначать сенаторов принадлежало ранее царю, а затем консулам. По Закону Овидия (последняя четверть IV в.) это право перешло к цензорам. Закон Овидия установил, «чтобы цензоры под клятвой выбирали в сенат лучших из всех категорий магистратов». Должности замещались в определенном порядке. Обычный порядок был такой: квестор - трибун плебса (необязательно) - курульный эдил - претор - цензор [7].

На основании вышеизложенного можно выделить основные ключевые характеристики сената:

- не был выборным органом;

- ему принадлежала административная власть в период так называемого "вакуума власти», когда своевременно не мог быть избран высший магистрат;

- осуществлял руководство иностранными делами страны;

— решал вопросы объявления войны и заключения мира;

- ратифицировал мирные договоры;

- осуществлял общее руководство вооруженными силами;

- составлял бюджет расходов и доходов;

- руководил государственным имуществом, распоряжаясь захваченными у других народов землями;

- ведал «светскими» делами религиозного культа: устанавливал религиозные праздники, принимал решение об их организационном обеспечении и т.п.

Магистратура.Вэпоху республики вся высшая власть в Древнем Риме принадлежала выборным должностным лицам - магистратам («magistratus»). Все магистратуры были коллективными, члены которых назывались коллегами. Система магистратур сложилась окончательно в IV в. до н.э. В состав магистратуры входили должностные лица, которые выполняли свои функции безвозмездно, то есть избрание на должность рассматривалось как право и почетная обязанность римского гражданина.

Высшие магистраты республики («magistratus majores») - консулы и преторы были носителями «империо» («imperium»). Они воплощали высшую гражданскую и военную власть в Римской республике, однако ни один из них не имел той полноты власти, которой обладал царь. Квесторы и эдилы, то есть нижние магистратуры, не обладали «империо». Не были выразителями «импе- рио» («imperium») и цензоры, хотя эта должность очень почиталась в римском обществе в эпоху республики.

Магистраты избирались народным собранием. Сенат объявлял о начале избирательной кампании за три нундины (от 17 до 25 дней). Каждый кандидат выдвигал свою кандидатуру на Форуме и надевал белую тогу-кандида и в сопровождении раба номенклатора, который знал всех избирателей поименно, агитировал за свою кандидатуру. Таким путем избирались все ординарные магистраты, в том числе и консулы [8].

Специальный закон («lex Vullla annalls») впервые определил «возраст, в котором можно претендовать на должность магистрата и занимать ее». Выдвигать свою кандидатуру мог только полноправный и свободнорожденный римский гражданин, здоровый телесно и умственно, к чему в реальности присоединялось требование о существовании значительного имущественного положения. Выбирать можно было только представителей знати, которым были «открыты двери сената». Римские магистраты ни были обычными чиновниками. Каждый из них представлял собой часть царского величия, и вместе с римским народом, они были носителями государственного «величия». Магистраты несли ответственность перед народом. Условием, которое фактически ограничивало возможность произвола со стороны магистрата, было то, что все они за свои должностные действия могли быть привлечены к суду Народного Собрания.

Во время выполнения полномочий магистраты пользовались иммунитетом, и все граждане обязаны были относиться к ним с уважением, поскольку они олицетворяли суверенную волю римского народа («majestas»).

Институт консулов занимал особое место в политико-правовой системе Римской республики. Должность консула была утверждена в Риме после изгнания царя в 509 гг. до н.э. Будучи верховными правителями, консулы осуществляли всю полноту исполнительной власти - как в гражданской, так и в военной сфере. Сначала высших государственных магистратов называли термином претор (от «praeire» - «идти вперед») [9]. Вероятнее всего, на раннем этапе развития республики в Риме существовала коллегия двух или трех преторов во главе с «praetor maximus».

Власть консула была ограничена его коллегой, другим консулом, наделенным правом вмешиваться в действия своего коллеги (право интерцессии). Действующий консул имел право наложить запрет на решение своего коллеги или иного магистрата, за исключением цензора или диктатора. Для решения проблемы и предотвращения кризисных ситуаций в случае интерцессии 
римляне обращались к божественным знамениям или бросали жребий.

К тому же, было еще несколько факторов, которые ограничивали действие консулов. Во-первых, создание магистратуры квесторов (509 г. до н.э.), которые руководили финансами и бюджетом. Во-вторых, власть народных трибунов (494 г. до н.э.), имевших право интерцессии. В-третьих, организация специальной магистратурыцензуры (443 г. до н.э.) для осуществления ценза. По закону Овиния, цензоры от консулов получили полномочия составлять списки сенаторов. В-четвертых, введение должности преторов, полномочия которых распространялись на гражданскую юрисдикцию. В-пятых, право обращения к народу («jus provocationis») [10].

Итак, на основе использования и ознакомления с материаламии данными из исторических источников, а также в процессе изучения специализированной ли- тературы всестороннему научному анализу была подвергнута проблема политического устройства и политической структуры Римской империи V-VI вв. до н.э. При этом главное внимание было уделено тем аспектам проблемы, которые недостаточно освещены современниками историками или вызывают среди них активные дискуссии.

В процессе исследования установлено, что в состав органов управления входили народное собрание, сенат, магистратура. В основе Римской республики как политической системы лежало сакральное понятие «imperium», которым определялась полнота высшей исполнительной власти в гражданской и военной сферах. Вместе с тем следует отметить, что политически-правовая система Древнего Рима не оставалась неизменной. История сената, магистратур отражает процессы, которые происходили в римском обществе на протяжении веков.

\section{ЛИТЕРАТУРА}

1. Power and public finance at Rome, 264-49 BCE / James Tan.NewYork, NY: Oxford University Press, 2017. $214 \mathrm{p}$.

2. Architecture and politics in Republican Rome / Penelope J. E. Davies, The University of Texas at Austin.NewYork: Cambridge University Press, 2017.366 p.

3. The ancient Romans: a social and political history from the early Republic to the death of Augustus / Matthew Dillon, Lynda Garland. London: Routledge, 2015. $425 \mathrm{p}$.

4. Reconstructing the Roman republic: an ancient political culture and modern research / Karl-J. Hölkeskamp; translated by Henry Heitmann-Gordon; revised, updated, and augmented by the author.Princeton, N.J.; Woodstock: PrincetonUniversityPress, 2010. 189 p.

5. Law and power in the making of the Roman commonwealth / Luigi CapogrossiColognesi; translated by Laura Kopp. Cambridge, United Kingdom: Cambridge University Press, 2014.370 p.

6. Ижаева Л.Э. Правовые явления: правоспособность, дееспособность и правовой статус в праве Древнего Рима // Наука Парк, 2018 , № 5 (66). С. $27-29$.

7. Adamson, Jordan Political institutions, resources, and war: Theory and evidence from ancient Rome // Explorations in economic history, 2020, Volume 76. pp. 79-82.

8. Волошин Д.А. Феномен империи в мировой истории: Рим // Хроники объединенного фонда электронных ресурсов Наука и образование, 2014, № 5 (60). C. 16.

9. Пономарева М.С. Государственный строй Римской Республики // Аллея науки, 2019. Т. 1. № 5 (32). С. 635-637.

10. Ткаченко Д.Н. Предоставление проконсульской власти в Римской Республике // Вестник Ярославского государственного университета им. П. Г. Демидова. Серия Гуманитарные науки. 2018. № 1 (43). С. 48-50.

(с) Ковалев Станислав Сергеевич (stanis12021@yandex.ru).

Журнал «Современная наука: актуальные проблемы теории и практики» 